\title{
Anti-microtubule activity of tubeimoside I and its colchicine binding site of tubulin
}

\author{
Rundi Ma · Gang Song · Wenbing You · Lijian Yu • \\ Weiming Su • Mingneng Liao · Yongping Zhang • \\ Laizhen Huang · Xiaoyu Zhang · Tingxi Yu
}

Received: 3 July 2007 / Accepted: 24 October 2007/Published online: 21 November 2007

(C) The Author(s) 2007

\begin{abstract}
Background Tubeimoside I (TBMS1) was isolated from the tubers of Bolbostemma paniculatum (Maxim.) Franquet. TBMS1 shows potent anti-tumor activity. The present study was conducted to investigate the anti-microtubule role of TBMS1 and its binding site of tubulin.

Methods Cell growth inhibition was measured by MTT after treatment with TBMS1. Uptake kinetics of TBMS1 by human nasopharyngeal carcinoma CNE-2Z cell line (CNE-2Z) was assayed by HPLC. Microtubule protein (MTP) was prepared from porcine brain through two cycles of polymerization-depolymerization in a high molarity buffer. Inhibition of MTP polymerization induced by TBMS1 was determined by a turbidity measurement and a sedimentation assay; the interactions of TBMS1 with tubulin within CNE-2Z cells were investigated by immunofluorescence microscopy and immunoblotting. TBMS1
\end{abstract}

Rundi Ma, Lijian Yu, Xiaoyu Zhang and Tingxi Yu contributed equally to this work.

R. Ma · G. Song · W. You $\cdot$ L. Yu $(\bowtie) \cdot$ W. Su $\cdot$ M. Liao

Y. Zhang $\cdot$ L. Huang $\cdot$ X. Zhang $\cdot$ T. Yu

Key Laboratory of Marine Materia Medica,

Guangdong Ocean University, Jiefang East Avenue 40,

Xiashan, Zhanjiang 524025, China

e-mail: ywyj9578@sohu.com

T. Yu

Department of Molecular Microbiology and Immunology, Public Health, Johns Hopkins University, Baltimore, MD 21205, USA

\section{Zhang}

Department of Otorhinolaryngology,

Head and Neck Surgery, University of Maryland School

of Medicine, Baltimore, MD 21228, USA was tested for its ability to inhibit binding of known tubulin ligands through competitive binding assay.

Results TBMS1 displayed growth inhibitory activity against CNE-2Z cells with $\mathrm{IC}_{50}$ value of $16.7 \mu \mathrm{M}$ for $72 \mathrm{~h}$. HPLC analysis of TBMS1 uptake by CNE-2Z cells displayed the initial slow TBMS1 uptake and then gradually reaching an maximum uptake near $18 \mathrm{~h}$. CNE-2Z cells treated with TBMS1 $(25 \mu \mathrm{M}, 3 \mathrm{~h})$ were sufficient to cause the microtubular network disruption. Immunoblot analysis showed that the proportion of cytosolic tubulin of cells treated with TBMS1 increased in a time- and concentration-dependent manner. TBMS1 did not inhibit the binding of vinblastine to tubulin. Colchicine binding to tubulin was inhibited in the presence of TBMS1.

Conclusions TBMS1 is an anti-microtubule agent, and its binding site of tubulin is the colchicine binding site of tubulin.

Keywords Bolbostemma paniculatum (Maxim.)

Franquet · Tubeimoside I · Uptake kinetics ·

Anti-microtubule activity .

Colchicine binding site of tubulin

\section{Introduction}

“Tu-Bei-Mu”, Bolbostemma paniculatum (Maxim.) Franquet (Cucurbitaceae) is a traditional Chinese medicinal plant, which was listed in the Supplement to the Compendium of Materia Medica, compiled in 1765, at the time of the Qing Dynasty. Its stem tuber was employed, for example, in the treatment of breast carcinoma, mammary abscess, cyclomastopathy and tuberculosis of lymph node, in ancient times, and was very effective in resolving masses and reducing swellings [1]. Some physicians of 
traditional Chinese medicine in Sichuan and Shaanxi provinces used to apply it to treatment of esophagus carcinoma and stomach cancer with considerable efficiency during the 70s of last century, but the side-effects, such as nausea, vomiting, etc., were quite serious. Tubeimoside I (TBMS1), a bisdesmosidic triterpenoid saponin whose sugar chains are connected by 3-hydroxyl-3-methylglutaric acid to form a unique macrocyclic structure, was isolated from the tubers of Bolbostemma paniculatum (Fig. 1) $[2,3]$. Our previous studies demonstrated that TBMS1 had potent anti-tumor, anti-tumor-promoting, and anti-metastatic activities [4-7], and induced cell cycle arrest and apoptosis in human promyelocytic leukemia (HL-60) [8], and HeLa cells [9], and nasopharyngeal carcinoma CNE-2Z cell line (CNE-2Z) [10].

Normal cell division, intracellular transport, cellular motility, cell signaling, and maintenance of cell shape are all dependent on highly regulated dynamic instability process of the tubulin/microtubule system. Microtubules are hollow tubes consisting of $\alpha$ - and $\beta$-tubulin heterodimers that polymerize parallel to a cylindrical axis. Mitotic microtubules are very dynamic structures, switching between growing and shortening states, a process known as dynamic instability and driven primarily by the catastrophe rate. Microtubule-associated proteins (MAPs) bind to and stabilize microtubules by reducing the catastrophe rate or increasing the polymerization rate.

Microtubule poisons like the Vinca alkaloids and colchicines have been known for decades for their

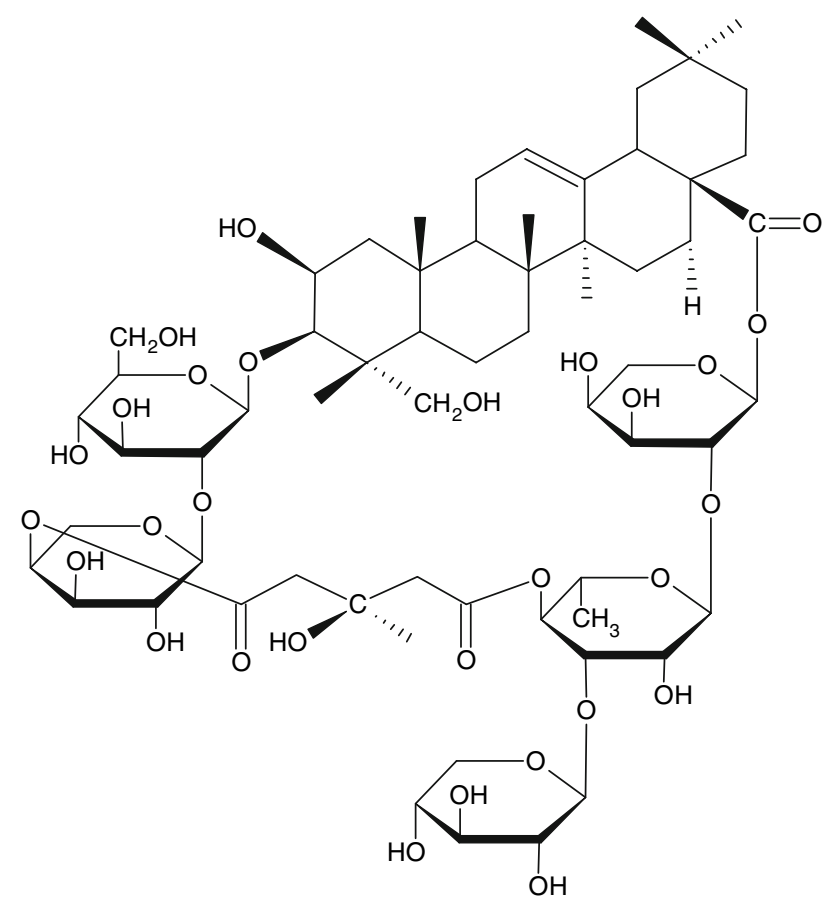

Fig. 1 Chemical structural formula of TBMS1 depolymerizing effects on microtubules. In 1980, the mechanism of action of the cytotoxic anti-tumor agent Taxol was discovered [11]. Taxol, unlike other microtubule-interacting agents previously identified, promotes the polymerization of tubulin into microtubules. The mechanism of action of paclitaxel has been well documented and includes the premature polymerization of tubulin resulting in hyperstable microtubule formation, inhibition of cellular proliferation at the $G_{2} / M$ phase of the cell cycle, mitotic spindle disorganization, and cell death. Taxol is clinically effective anti-cancer agent and represents perhaps the most significant addition to the pharmacopoeia of cancer chemotherapeutic agents in the last decade [12]. Prompted by the clinical successes of the taxanes, Taxol ${ }^{\mathrm{TM}}$ (paclitaxel) and Taxotere ${ }^{\mathrm{TM}}$ (docetaxel), significant efforts have been focused on identifying new agents that have a similar mechanism of action yet superior properties such as agents that are poor substrates of Pgp4-mediated transport and exhibit better solubility in aqueous solutions. The discovery of new natural and semisynthetic compounds being cytotoxic by interference with tubulin have attracted much attention within the last years, the microtubule complex has thus proven to be a compelling target for the development of anti-cancer therapeutic agents [13,14].

Our recent studies showed that TBMS1 opens the permeability transition pore, thereby decreasing mitochondrial membrane potential, releasing cytochrome $\mathrm{c}$ from mitochondria, and further causing a series of events consistent with established mechanistic models of apoptosis. An important point to be stressed is that the effects of TBMS1 on mitochondria and mitochondrial cytochrome c were observed at rather high concentrations of TBMS1 $(>20 \mu \mathrm{M})$ [15]. Therefore, only the effects of TBMS1 on mitochondria and mitochondrial cytochrome $\mathrm{c}$ are not sufficient to explain the mechanisms of TBMS1-induced apoptosis in human tumor cells. Since TBMS1 is capable of inhibiting angiogenesis [16], and certain relationship exists between anti-angiogenesis and anti-microtubule effects of drugs [17], it is interesting to study the antimicrotubule activity of TBMS1 and its binding site of tubulin.

\section{Materials and methods}

Collection of "Tu-Bei-Mu" and preparation of TBMS1

"Tu-Bei-Mu" was collected at Shaanxi Province (China), and identified by Professor Quan Y (Department of Botany, Shaanxi Provincial Academy of Traditional Chinese Medicine and Pharmacy, China). A voucher specimen (No. 097) has been deposited in the Key Laboratory of Marine Materia Medica, Guangdong Ocean University, Zhanjiang 
524025, China. TBMS1 was isolated from tubers of $B$. paniculatum (Maxim.) Franquet (Cucurbitaceae) by the method reported previously [2, 3]. Its structural formula was established by Kong et al. [3]. The purity of TBMS1 was $>98.5 \%$ (estimated by HPLC). The purified TBMS1 was solubilized in distilled water, and the stock solutions were stored at $-20^{\circ} \mathrm{C}$ with no evidence of chemical degradation over time.

\section{Chemicals}

Paclitaxel, colchicine, Vinblastine, adenosine $5^{\prime}$-triphosphate (ATP), guanosine triphosphate (GTP), ethyleneglycol$\operatorname{bis}\left(\beta\right.$-aminoethylether)- $N, N, N^{\prime}, N^{\prime}$-tetra acetic acid (EGTA), and 2-[N-morpholino]ethanesulfonic acid (MES), PIPES and Triton X-100 were purchased from Sigma Chemical Co. Mouse monoclonal anti-tubulin antibody was obtained from NeoMarkers Corp. Nitrocellulose membranes were the product of Pall Corp. Super ${ }^{\mathrm{B}}$ West Pico kit was obtained from Pierce Corp. $\left[{ }^{3} \mathrm{H}\right]$ vinblastine $(8 \mathrm{Ci} / \mathrm{mmol})$ and MicroSpin ${ }^{\mathrm{TM}}$ G-50 (superfine) were purchased from Amersham, and $\left[{ }^{3} \mathrm{H}\right]$ colchicine $(70 \mathrm{Ci} / \mathrm{mmol})$ was purchased from DuPont. RPMI-1640 medium was purchased from HyClone Co. Newborn calf serum (NCS) was obtained from Sijiqing Biological Material Co. (Hangzhou, China). All other chemicals used were of reagent grade.

\section{Cell line and cell culture}

The CNE-2Z cell line from a Cantonese patient established by $\mathrm{Gu}$ et al. [18] was obtained from Guangdong Medical College. Cells were cultured in RPMI-1640 medium supplemented with $10 \%$ (v/v) heat-inactivated NCS, $100 \mathrm{U} / \mathrm{ml}$ penicillin, $100 \mu \mathrm{g} / \mathrm{ml}$ streptomycin and $2 \mathrm{~g} / 1 \mathrm{NaHCO}_{3}$ at $37^{\circ} \mathrm{C}$ in humidified air containing $5 \% \mathrm{CO}_{2}$ in monolayer. Cells in log phase growth were used in the experiments.

\section{MTT assay}

The mitochondrial metabolism of 3-(4,5-dimethylthiazol2-yl)-2,5-diphenyltetrazolium bromide (MTT) to its insoluble blue formazan was used for enumerating cells to assess the anti-proliferative effects of TBMS1 according to the methods of Hansen et al. [19]. Briefly, Single-cell suspensions were prepared and seeded into 96 well microculture plates with $1.0 \times 10^{5}$ cells $/ \mathrm{ml}(90 \mu \mathrm{l} /$ well $)$. Cells were cultured for $12 \mathrm{~h}$ before addition of TBMS1. TBMS1 was diluted into RPMI-1640 medium and added to each well in a volume of $10 \mu \mathrm{l}$. Cells were incubated at $37^{\circ} \mathrm{C}$ for the time indicated. MTT solution $(5 \mathrm{mg} / \mathrm{ml})$ was aliquoted to each well in a volume of $20 \mu \mathrm{l}$, and $5 \mathrm{~h}$ later $100 \mu \mathrm{l}$ of the solubilization solution $[10 \%$ SDS-5\% isobutyl alcohol-0.012 $\mathrm{M} \mathrm{HCl}(\mathrm{w} / \mathrm{v} / \mathrm{v})]$ was added into each well. The plates were allowed to stand overnight in the incubator in a humidified atmosphere. Absorbance at $570 \mathrm{~nm}\left(\mathrm{~A}_{570}\right)$ was determined for each well using an ELISA reader. Control wells contained all of the agents presented in the treated wells except TBMS1. Each experimental point was performed in three replicates. The $50 \%$ inhibitory concentration $\left(\mathrm{IC}_{50}\right)$ was determined from dose-response data from at least three experiments.

\section{Uptake of TBMS1 by CNE-2Z cells}

CNE-2Z $\left(5 \times 10^{5}\right)$ cells were cultured with a final concentration of TBMS1 of $30 \mu \mathrm{M}$ at $37^{\circ} \mathrm{C}$, pH 7.4. Samples were taken at specified time intervals and the supernatant was seperated by centrifugation for $5 \mathrm{~min}$ at room temperature and 7,500g in an Eppendorf 3200 centrifuge. The CNE-2Z cell fraction was resuspended in about 10 vol. of cold PBS and seperated by the short centrifugation three times described above, and the concentrated cells were resuspended in deionized water and homogenized by sonication. The supernatant was obtained by centrifugation at $2,000 \mathrm{~g}$ for $5 \mathrm{~min}$, and then deproteinized with $10 \%$ (W/V) trichloroacetic acid. The methanolic extracts were used for the assays of TBMS1 concentrations by HPLC using Hypersil ODS column $(5 \mu \mathrm{m} 4.0 \times 250 \mathrm{~mm})$ [20].

\section{MTP preparation and purification}

Microtubule protein (MTP) was prepared and purified from fresh porcine brains through two cycles of polymerizationdepolymerization in a high molarity PIPES buffer. Fresh brains were obtained from a local abattoir and put into a bag in ice to be transferred quickly to the laboratory as soon as the pig was butchered. The blood vessels, meninges and other impurities were removed after weighing. The preparation and purification of MTP were performed according to the methods of Castoldi and Popov [21]. The solution of MTP was stored in liquid nitrogen as 1-2 ml aliquots until used. The protein content was estimated by Lowry's method [22] using bovine serum albumin as a standard.

The composition of MTP, which is composed of tubulin and MAPs, was investigated by densitometry of a Coomassie brilliant blue-stained sodium dodecylsulphate polyacrylamide gel electrophoresis (SDS-PAGE) gel. Tubulin identity was confirmed with a commercial antitubulin antibody by immunoblotting.

Eight or sixteen micrograms sample (final volume $8 \mu \mathrm{l}$ ) was mixed with $2 \mu \mathrm{l} 5 \times$ sample-dissociating buffer and 
boiled for $4 \mathrm{~min}$. These samples were loaded on $10 \%(\mathrm{w} / \mathrm{v})$ SDS-polyacrylamide gel and electrophoresis was performed. Proteins were transferred to nitrocellulose membranes by electroblotting. The membrances were blocked with $10 \%(\mathrm{w} / \mathrm{v})$ fat-free milk and incubated with the monoclonal mouse anti-tubulin antibody (at 1:500 dilution) in 5\% (w/v) fat-free milk in TTBS buffer $(150 \mathrm{mM}$ $\mathrm{NaCl}, 50 \mathrm{mM}$ Tris-HCl, $\mathrm{pH} 7.5,0.05 \% \mathrm{v} / \mathrm{v}$ Tween-20) for $2 \mathrm{~h}$ at room temperature. The immunoreactive proteins were probed with horseradish peroxidase-conjugated goat anti-mouse $\operatorname{IgG}$, protein levels were visualized by peroxidase reaction using Super ${ }^{\mathbb{R}}$ West Pico kit.

\section{Microtubule assembly assay}

The microtubule assembly was monitored spectroscopically by turbidity measurement at $350 \mathrm{~nm}$ using a spectrophotometer (UV-1601, SHIMADZU, Japan) equipped with a thermostatically regulated liquid circulator [23]. The constituents of the assay (freshly thawed MTP, ATP, MES buffer and test compounds) and cuvettes were kept cold on ice. Paclitaxel, as a positive control, was dissolved in dimethyl sulfoxide (DMSO) and the stock solution was diluted with MES buffer. Colchicine, which was the other positive control, and TBMS1 were dissolved in MES buffer. Stock solutions of MTP were diluted on ice in cold MES buffer to a final concentration of $1.12 \mathrm{mg} / \mathrm{ml}$. The instrument was zeroed with this solution at $0^{\circ} \mathrm{C}$. Test compounds (final concentrations ranged from 2.5 to $40 \mu \mathrm{M})$ were then quickly mixed into the MTP solution. The final volume of the reaction mixtures was $250 \mu \mathrm{l}$. Assembly was initiated by warming the solution from 0 to $37^{\circ} \mathrm{C}$ and the polymerization process was monitored by observing the variations in absorbance at $350 \mathrm{~nm}$. After $16 \mathrm{~min}$ at $37^{\circ} \mathrm{C}$, the absorbance $\left(\mathrm{A}_{350}\right)$ reached a plateau. The temperature was held at $37^{\circ} \mathrm{C}$ for more $20 \mathrm{~min}$, and then was rapidly lowered back to $0^{\circ} \mathrm{C}$. The assay was over after incubation at $0^{\circ} \mathrm{C}$ for $20 \mathrm{~min}$. The absorbance readings were taken every 3 min throughout the incubation time. The temperature was held at $37^{\circ} \mathrm{C}$ for $20 \mathrm{~min}$ and the changes in absorbance was used to calculate the extent of polymerization $\left[(\%)\right.$ inhibition $=\left(1-\mathrm{A}_{350}\right.$ sample $/ \mathrm{A}_{350}$ control) $\times 100 \%]$.

\section{Sedimentation assay}

The assay was performed as described by Mitsui-Saito et al. [24]. In the assay, polymerized and non-polymerized tubulin were separated by ultracentrifugation. The samples ( $250 \mu \mathrm{l}, 1.12 \mathrm{mg} \mathrm{MTP} / \mathrm{ml}$ ) were incubated in the presence or absence of test compounds (paclitaxel and colchicine, final concentration at $2.5 \mu \mathrm{M}$; TBMS1, final concentration at $10 \mu \mathrm{M}$, respectively) for $20 \mathrm{~min}$ at $37^{\circ} \mathrm{C}$, and centrifuged at $105,000 \mathrm{~g}$ at $37^{\circ} \mathrm{C}$ for $1 \mathrm{~h}$. The supernatant was removed and the pellets were homogenized in $250 \mu \mathrm{l}$ MES buffer. Twenty microlitters homogenate was mixed with sample-dissociating buffer and boiled for $4 \mathrm{~min}$. These samples were loaded on $10 \%(\mathrm{w} / \mathrm{v})$ SDS-polyacrylamide gel and electrophoresis was performed. The gel was stained with Coomassie brilliant blue.

Immunofluorescence microscopy

Microtubular cytoskeleton was observed according to the methods of Isbrucker et al. [25]. CNE-2Z cells were seeded on sterile glass coverslips in 6-well tissue culture plate at a density of $2.5 \times 10^{5}$ cells/well and allowed to adhere and grow for $24 \mathrm{~h} \mathrm{at} 37^{\circ} \mathrm{C}, 5 \% \mathrm{CO}_{2}$. Attached cells were treated with or without test compounds for $3 \mathrm{~h}$. The culture medium was removed and cells were rinsed with phosphate-buffered saline (PBS) prior to fixation in $4 \%(\mathrm{v} / \mathrm{v})$ formaldehyde in PBS for $10 \mathrm{~min}$ at room temperature. The fixed cells were rinsed with PBS three times and permeabilized in $0.5 \%(\mathrm{v} / \mathrm{v})$ Triton X-100 in PBS for $10 \mathrm{~min}$ and rinsed four times again in PBS (every rinse needed $10 \mathrm{~min})$. Cells were incubated with PBS containing 10\% (v/v) NCS for 10 min to block non-specific binding sites before incubation for $45 \mathrm{~min}$ with the primary antibody (mouse monoclonal anti-tubulin antibody, diluted at 1:400 in $10 \% \mathrm{w} / \mathrm{v}$ fat-free milk). Following three rinses in PBS containing $1 \%(\mathrm{v} / \mathrm{v})$ Triton X-100, cells were incubated with the secondary antibody in the dark for $45 \mathrm{~min}$ (fluorescein isothiocyanate-conjugated goat anti-mouse IgG, diluted at 1:150 in 10\% w/v fat-free milk). All incubations were carried out at room temperature with intermittent shaking. Cells were then gently rinsed three times $(10 \mathrm{~min}$ each) in $2 \mathrm{ml}$ of PBS containing 1\% (v/v) Triton X-100 in the dark. The coverslips were examined with Leica fluorescence microscope (DMIRB, Leica Microsystems, Germany) equipped with appropriate filter sets. Photographs were taken with a Nikon camera, using Kodak Gold 400 film, magnification $400 \times$.

Analysis of soluble and polymerized tubulin by immunoblotting

CNE-2Z cells were seeded at $1 \times 10^{5}$ per $\mathrm{ml}$ in tissue culture flasks. Paclitaxel $(2.5 \mu \mathrm{M})$, colchicine $(2.5 \mu \mathrm{M})$, TBMS1 $(10,25 \mu \mathrm{M})$ or vehicle was added to flasks containing cells growing in log phase, respectively. Paclitaxel was dissolved in DMSO and then further diluted to final concentration in culture medium. Colchicine and TBMS1 
were dissolved in serum-free and antibiotic-free RPMI1640 medium to yield final concentrations. Soluble (cytosolic) and polymerized (cytoskeletal) fractions of tubulin were separated according to the methods of Kavallaris et al. [26] with some modifications. Briefly, after cells were treated with the drugs for specified time intervals, they were harvested and washed twice with cold PBS. Cells were lysed at $37^{\circ} \mathrm{C}$ for $10 \mathrm{~min}$ in the dark with $300 \mu \mathrm{l}$ hypotonic buffer $(1 \mathrm{mM} \mathrm{MgCl} 2,2 \mathrm{mM}$ EGTA, $0.5 \% \mathrm{v} / \mathrm{v}$ Nonidet P-40, $5 \mathrm{mM} \varepsilon$-amino-caproic acid, $0.01 \mathrm{nM}$ benzamidine, $20 \mathrm{mM}$ Tris- $\mathrm{HCl}$, pH 6.8, containing $20 \mu \mathrm{g} / \mathrm{ml}$ aprotinin, $2 \mathrm{mM}$ phenylmethylsulfonyl fluoride, $1 \mathrm{mM}$ sodium orthovanadate and $100 \mu \mathrm{g} / \mathrm{ml}$ soybean trypsin inhibitor). Soluble tubulin was collected in the supernatant following centrifugation $18,000 \mathrm{~g}$ for $10 \mathrm{~min}$ at room temperature. The pellets were resuspended in $100 \mu \mathrm{l}$ cold hypotonic buffer and incubated on ice for $30 \mathrm{~min}$. Insoluble material was removed by centrifugation at $4^{\circ} \mathrm{C}$ for $5 \mathrm{~min}$ at $200 \mathrm{~g}$. The resulting supernatant contained the polymerized tubulin. Protein concentrations were determinded using the Lowry's method [22]. Immunoblotting was performed as described above.

Effect of TBMS1 on vinblastine or colchicine binding to tubulin [27-30]

Each $0.5 \mathrm{ml}$ reaction contained 0.1 M MES (pH 7.0 with $\mathrm{NaOH}$ in $1 \mathrm{M}$ stock solution), $0.5 \mathrm{mM} \mathrm{MgCl} 2,1.0 \mathrm{mg} / \mathrm{ml}$ of tubulin, $\left[{ }^{3} \mathrm{H}\right]$ Vinblastine or colchicine $(1-5 \mu \mathrm{M})$ and the indicated concentration of TBMS1 $(0,10,20,40 \mu \mathrm{M})$. Tubulin was added last in every experiment and allowed to incubate at $37^{\circ} \mathrm{C}$ for $45 \mathrm{~min}$ (for vinblastine) or for $120 \mathrm{~min}$ in the dark (for colchicine). Reaction mixtures were then added to $1 \mathrm{ml}$ microspin columns of Sephadex G-50 (superfine) and processed by centrifugal gel filtration at room temperature. The filtrate was collected, and radioactivity was determined by liquid scintillation counting, allowing calculation of a mole ratio of drug to tubulin for each experiment. Controls determined that no radioactivity passed through the column in the absence of tubulin. All lines were drawn by linear regression, each regression line represents data from a minimum of three individual experiments.

\section{Results}

Inhibition of CNE-2Z cell growth by TBMS1

Inhibition of cell growth was observed following treatment of different doses of TBMS1 for 24, 48, $72 \mathrm{~h}$. The inhibitory activity was dose- and time-dependent (Fig. 2), and the estimated $\mathrm{IC}_{50}$ values after $24,48,72 \mathrm{~h}$ of TBMS1

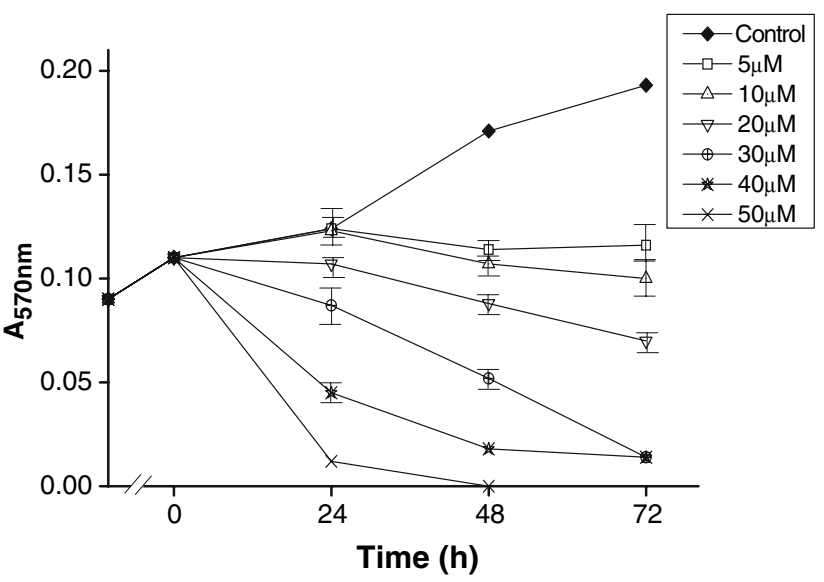

Fig. 2 Dose- and time-response of TBMS1 on growth of CNE-2Z cells. CNE-2Z cells were treated with various concentration of TBMS1 for different time intervals. The cell proliferation was determined by MTT assay. The values are expressed as mean $\pm \mathrm{SE}$ of three independent experiments

treatment were $32.5,20.7,16.7 \mu \mathrm{M}$. All the experiments were repeated at least three times.

Uptake of TBMS1 by CNE-2Z cells and the uptake kinetics

HPLC analysis of TBMS1 uptake kinetics by CNE-2Z cells displayed the initial markedly slow TBMS1 uptake, and then gradually reaching an apparent maximum uptake near $18 \mathrm{~h}$ and a decrease in cellular uptake at $24 \mathrm{~h}$ suggesting the cells dying and leaky (Fig. 3).

\section{Identification of MTP}

The content of MTP was estimated to be $8 \mathrm{mg} / \mathrm{ml}$. The molecular weights of major components of MTP ranged from 44.0 to $66.2 \mathrm{kDa}$. Immunoblotting with anti-tubulin antibody confirmed the identity of the major protein band as tubulin (the $\alpha, \beta$-tubulin monomers have very similar molecular weights: about $55 \mathrm{kDa}$ ). Analysis of densitometry of the bands suggested that the purification procedure yielded a mixture of $>90 \%$ heterodimeric $\alpha, \beta$-tubulin (Fig. 4).

TBMS1-mediated inhibition of tubulin polymerization

The capacity of TBMS1 to inhibit MTP polymerization in vitro was determined by monitoring turbidity changes with temperature and time. The effect of TBMS1 on MTP polymerization was compared with those of controls. The results showed that $2.5 \mu \mathrm{M}$ paclitaxel induced polymerization of MTP remarkably, and the polymer was stabilized 


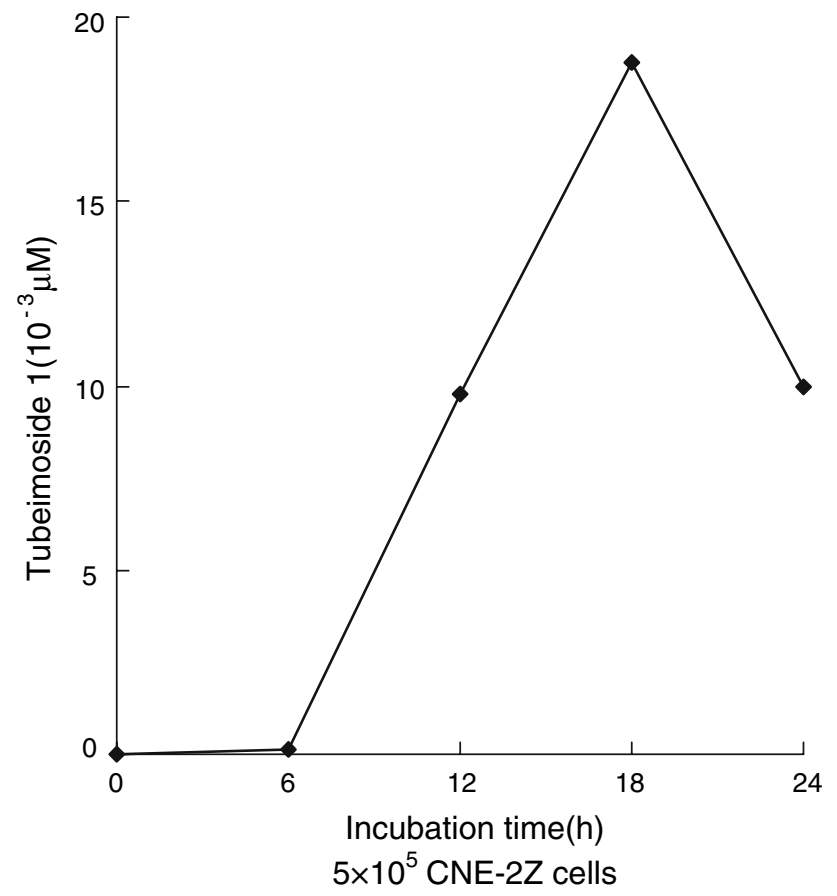

Fig. 3 Time course of TBMS1 uptake by CNE-2Z cells. CNE-2Z cells were cultured with a final concentration of TBMS1 of $30 \mu \mathrm{M}$. Samples were taken at specified time intervals and prepared as described in "Materials and methods". The methanolic extracts were used for the assays of TBMS1 concentrations by HPLC using Hypersil ODS column $(5 \mu \mathrm{m} 4.0 \times 250 \mathrm{~mm})$. HPLC analysis of time course of TBMS1 uptake by CNE-2Z cells displayed the initial markedly slow TBMS1 uptake, and then gradually reaching an apparent maximum uptake near $18 \mathrm{~h}$ and a decrease in cellular uptake at $24 \mathrm{~h}$ suggesting the cells dying and leaky

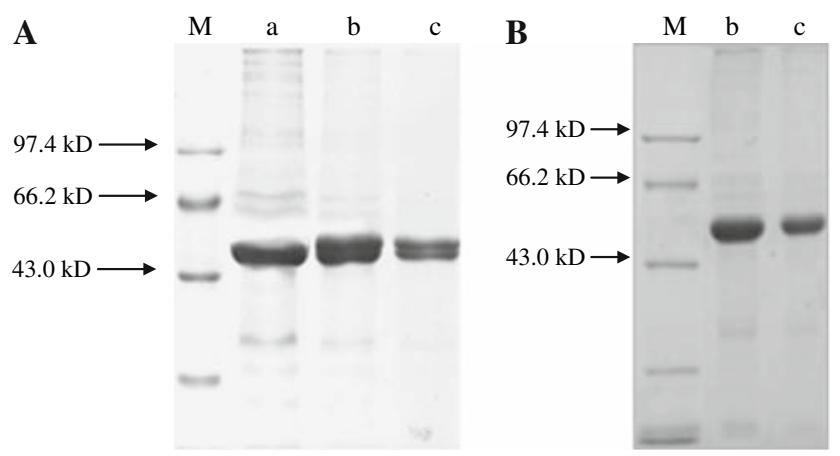

Fig. 4 Tubulin purity assessment: analysis by SDS-PAGE and immunoblotting. a A $10 \%$ gel stained with Coomassie brilliant blue. b A membrance probed with an anti-tubulin antibody. $M$ marker; lane a: $16 \mu \mathrm{g}$ sample of rude microtubulin protein preparation; lane $b$ : $16 \mu \mathrm{g}$ sample of microtubulin protein. Lane $c: 8 \mu \mathrm{g}$ sample of microtubulin protein. Analysis of densitometry of the bands suggested that the purification procedure yielded a mixture of $>90 \%$ heterodimeric $\alpha, \beta$-tubulin

by paclitaxel even at $0^{\circ} \mathrm{C}$, but at the same concentration, colchicine was effective at inhibiting polymerization of MTP, and produced a $71.3 \%$ inhibition of MTP polymerization (Fig. 5a). For TBMS1, it was effective at inhibition


Fig. 5 Effect of TBMS1 on the polymerization of MTP in vitro by turbidity measurement. Reaction mixtures containing MES buffer and $1.12 \mathrm{mg} / \mathrm{ml}$ MTP were held at $0^{\circ} \mathrm{C}$; at time zero, test compounds were added and mixed into the reaction mixture, and then the temperature was shifted to $37^{\circ} \mathrm{C}$. The turbidity of the solution was measured at an absorbance of $350 \mathrm{~nm}$ every $3 \mathrm{~min}$. At the time indicated by the arrow, the temperature of the reaction mixture was shifted at $0^{\circ} \mathrm{C}$. a MTP was incubated in the absence (-) or presence of $2.5 \mu \mathrm{M}$ paclitaxel (filled triangle), $2.5 \mu \mathrm{M}$ colchicine (open triangle) and $10 \mu \mathrm{M}$ TBMS1 $(\times)$; b MTP was incubated in the absence $(-)$ or presence of TBMS1 at concentrations of $5 \mu \mathrm{M}$ (filled circle), $7.5 \mu \mathrm{M}$ (open square), $10 \mu \mathrm{M}(\times), 20 \mu \mathrm{M}$ (filled diamond) and $40 \mu \mathrm{M}(+)$

of polymerization of MTP at all the concentrations tested, and at concentrations lower than $10 \mu \mathrm{M}$, the effect was dependent on concentration. Figure $5 \mathrm{~b}$ showed the concentration-dependent inhibition of MTP polymerization by TBMS1. Inhibition of MTP polymerization by TBMS1 could be distinguished at concentration as low as $5 \mu \mathrm{M}$, and the maximum inhibition of MTP polymerization occurred upon the addition of $40 \mu \mathrm{M}$ TBMS1. Inhibition rates $(\%)$ of TBMS1 at the concentrations of 5, 7.5, 10, 20, $40 \mu \mathrm{M}$ were $10.7,30.0,44.7,46.7$ and $49.3 \%$, respectively.

To further clarify the effect of TBMS1 on MTP polymerization, MTP polymerize in the presence or absence of $2.5 \mu \mathrm{M}$ paclitaxel, $2.5 \mu \mathrm{M}$ colchicine and $10 \mu \mathrm{M}$ TBMS1 at $37^{\circ} \mathrm{C}$ for $20 \mathrm{~min}$, and the amounts of polymerized 


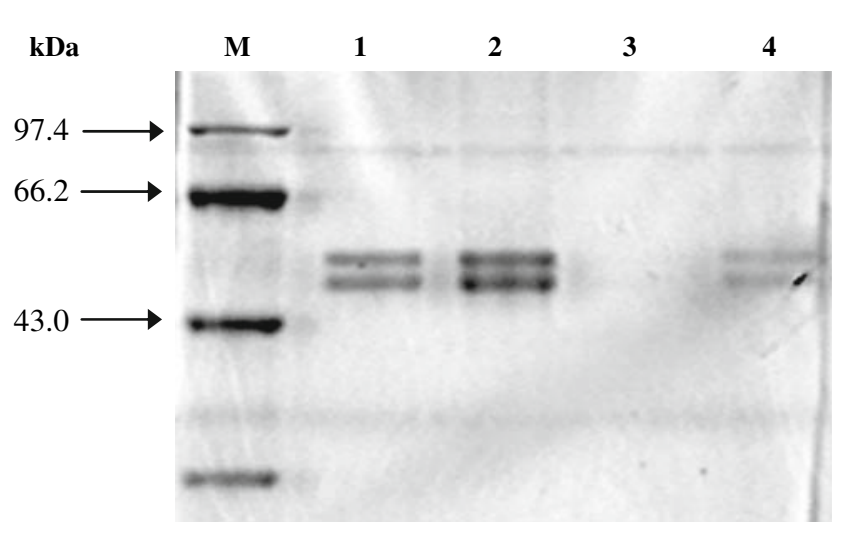

Fig. 6 Effect of TBMS1 on the polymerization of MTP by a sedimentation assay. MTP was incubated with or without test compounds at $37^{\circ} \mathrm{C}$ for $20 \mathrm{~min}$. The reaction mixture was ultracentrifuged and the pellets were separated by SDS-PAGE. The gel was stained with Coomassie brilliant blue. Tubulin (approximately $55 \mathrm{kDa})$ in lane $4(10 \mu \mathrm{M}$ TBMS1) is more than that in lane 3 ( $2.5 \mu \mathrm{M}$ colchicine), but less than that in lane 1 (untreated control). Paclitaxel $(2.5 \mu \mathrm{M})$ induced the most polymerization tubulin (lane 2 ). $M$ marker. The results of analysis of densitometry of the bands expressed as percent of the control value defined as $100 \%$ were given below: TBMS1 $(10 \mu \mathrm{M}), 34.6 \%$; colchicine $(2.5 \mu \mathrm{M}), 3.2 \%$; paclitaxel $(2.5 \mu \mathrm{M}), 196.4 \%$

fractions were visualized by SDS-PAGE followed by staining with Coomassie brilliant blue after separation using an ultracentrifuge. Obviously, the amount of polymerized tubulin induced by TBMS1 was more than that induced by colchicine, but less than that of the control, and much less than that induced by paclitaxel, and the results of analysis of densitometry of the bands expressed as percent of the control value defined as 100\% were given below:
TBMS1 $(10 \mu \mathrm{M}), 34.6 \%$; colchicine $(2.5 \mu \mathrm{M}), 3.2 \%$; paclitaxel $(2.5 \mu \mathrm{M}), 196.4 \%$ (Fig. 6). These results suggested that TBMS1 had direct inhibitory effect on polymerization of MTP in vitro, but the effect was relatively weak.

Interaction of TBMS1 with cellular microtubules

The interaction of TBMS1 with cellular microtubules was examined by immunofluorescence techniques in CNE-2Z cells. Untreated cells exhibited well-defined, cytoplasmic microtubule arrays radiating from the center to the cell periphery, and the control image demonstrated several dividing cells with normal spindles (Fig. 7a). Paclitaxel increased microtubule polymerization by promoting nucleation and elongation of the polymers and rearrangement of microtubules into bundle formations, stabilizing the microtubule lattice and bundling microtubules. Cellular microtubules of CNE-2Z cells treated with paclitaxel were abnormally assembled either in abundant arrays of disorganized microtubules in parallel "bundles" or in mitotic asters, and the microtubule bundles were predominant (Fig. 7b). Colchicine resulted in depolymerization of cellular microtubules, caused CNE-2Z cells to round up and the tubulin took on an amorphous appearance (Fig. 7c). The interaction of TBMS1 with tubulin within CNE-2Z cells was similar to that of colchicine. Treatment with TBMS1 $(25 \mu \mathrm{M}, 3 \mathrm{~h})$ induced a marked effect on the microtubular network. Under the experimental conditions, cells rounded, and were devoid of properly formed
Fig. 7 Immunofluorescence images of CNE-2Z cells treated with TBMS1. Cells were cultured for $24 \mathrm{~h}$ and then incubated without (a) or with $2.5 \mu \mathrm{M}$ paclitaxel (b), $2.5 \mu \mathrm{M}$ colchicine (c) and $25 \mu \mathrm{M}$ TBMS1 (d) for $3 \mathrm{~h}$. The fixed cells were stained with the antitubulin primary antibody and the fluorescein 5-

isothiocyanate-conjugated secondary antibody as described in "Materials and methods". Magnification $\times 400$

microtubules, and the cytoplasm was full of tubulin fluorescence (Fig. 7d). In addition, cells exposed to colchicine and TBMS1 were detached easier from the adherent coverslips than those untreated or treated with paclitaxel.

The effect of TBMS1 on tubulin was compared with those of paclitaxle and colchicine. Soluble and polymerized pools of tubulin were separated from cell lysates and the relative proportions were determined by Western blotting. The cells treated with paclitaxel greatly increased the amounts of polymerized tubulin compared to the control cells, whereas colchicine and TBMS1 increased the amounts of soluble tubulin, and $25 \mu \mathrm{M}$ TBMS1 induced more soluble tubulin than $10 \mu \mathrm{M}$ TBMS1. Furthermore, a shift in tubulin from a particulate to soluble form was observed after cells were treated with $25 \mu \mathrm{M}$ TBMS1 for 1 , 6,12 , or $24 \mathrm{~h}$, and the results suggested that at a certain concentration of TBMS1, soluble fractions of tubulin increased in a time-dependent manner (Fig. 8).

Effect of TBMS1 on vinblastine and colchicine binding to tubulin

Competitive binding assays using vinblastine and colcichine were employed to determine if TBMS1 occupied which one of these two known sites. The results obtained from this study showed that TBMS1 did not inhibit the binding of vinblastine to tubulin (data not shown). Detailed studies were performed to determine whether TBMS1 was a competitive inhibitor of colchicine binding, thus interacting at the colchicine site. In the Hanes format, these data yielded parallel curves at different TBMS1 concentrations



Fig. 8 Effect of TBMS1 on tubulin in CNE-2Z cells by immunoblotting. Total cellular protein $(30 \mu \mathrm{g} / \mathrm{lane})$ was separated on $10 \%$ SDS-PAGE, electrotransferred to nitrocellulose, and immunodetected with an anti-tubulin antibody. Lanes 1, 6: control, $24 \mathrm{~h}$; lane 2: $2.5 \mu \mathrm{M}$ paclitaxel, $24 \mathrm{~h}$; lane 3: $2.5 \mu \mathrm{M}$ colchicine, $24 \mathrm{~h}$; lanes 4,5 : 10, $25 \mu \mathrm{M}$ TBMS1, $24 \mathrm{~h}$; lanes 7-10: $25 \mu \mathrm{M}$ TBMS1, 1, 6, 12, $24 \mathrm{~h}$. $S$ soluble fractions of tubulin, $P$ polymerized fractions of tubulin
(Fig. 9a), consistent with competitive inhibition (with noncompetitive inhibition the curves intercept on the abscissa) [30]. Lineweaver-Burk analysis yielded lines that intercepted at positive abscissa, also indicating that this inhibition was competitive (Fig. 9b) [28]. Replotted in the Dixon format [31], the data yield an apparent $\mathrm{Ki}$ value of $57.9 \pm 5.0 \mu \mathrm{M}$ (average $\pm \mathrm{SD}$ ) for TBMS1.
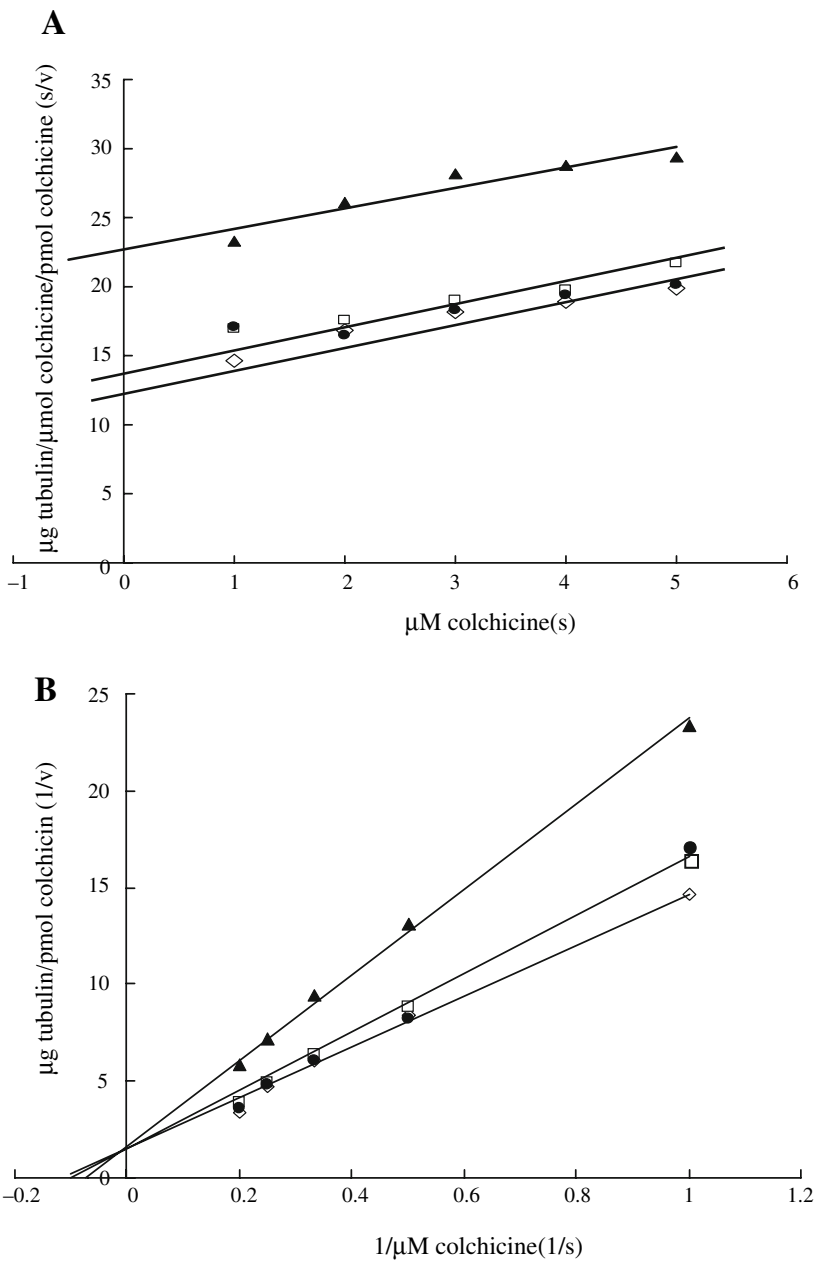

Fig. 9 Effect of TBMS1 on colchicine binding to tubulin. Each $0.5 \mathrm{ml}$ reaction mixture contained $0.1 \mathrm{M}$ MES ( $\mathrm{pH} 7.0$ with $\mathrm{NaOH}$ in $1 \mathrm{M}$ stock solution), $0.5 \mathrm{mM} \mathrm{MgCl} 2,1.0 \mathrm{mg} / \mathrm{ml}$ of tubulin, $\left[{ }^{3} \mathrm{H}\right]$ colchicine $(1-5 \mu \mathrm{M})$ and the indicated concentration of TBMS1. Tubulin was added last in every experiment and allowed to incubate at $37^{\circ} \mathrm{C}$ for $120 \mathrm{~min}$ in the dark. Reaction mixtures were then added to $1 \mathrm{ml}$ microspin columns of Sephadex G-50 (superfine) and processed by centrifugal gel filtration at room temperature. The filtrate was collected, and radioactivity was determined by liquid scintillation counting, allowing calculation of a mole ratio of drug to tubulin for each experiment. Controls determined that no radioactivity passed through the column in the absence of tubulin. For the experiment presented above the following concentrations of tubeimoside I were used: (open diamond) none; (filled circle) $10 \mu \mathrm{M} ;$ (open square) $20 \mu \mathrm{M}$; (filled triangle) $40 \mu \mathrm{M}$. All lines were drawn by linear regression, and $R^{2}$ values for all fits were above 0.97 . Each regression line represents data from a minimum of three individual experiments 


\section{Discussion}

Of particular interest has been the search for the cellular and molecular mechanisms underlying the anti-tumor effects of TBMS1. In the present study, we demonstrated inhibitory effect of TBMS1 on polymerization of MTP and uptake by tumor cells in vitro, and revealed that TBMS1 resulted in depolymerization of cellular microtubules and increase of the amount of soluble tubulin in CNE-2Z cells, and that TBMS1 was a competitive inhibitor of colchicine binding. These findings suggest that TBMS1 is an antimicrotubule agent, and its binding site of tubulin is the colchicine binding site of tubulin. TBMS1 as a natural product anti-microtubule agent adds to the growing list of agents with this mechanism of action, but the impression that we obtain from this study is that TBMS1 is a weak tubulin inhibitor, although any new natural product that has this mechanism of action has inherent interest.

TBMS1 has a core structure that is reminiscent of a steroid molecule. TBMS1 shares obvious structural homology with 2-methoxyestradiol and analogues, which cause microtubule depolymerization, and inhibition of the assembly of purified tubulin [32], and with taccalonolides, plant-derived steroid-like molecules that induce tubulin assembly and cause an increased density of celluar microtubules in interphase cells and the formation of thick bundles of microtubules similar to effects of Taxol [33]. In addition, bicyclic peptides celogentins $\mathrm{A}-\mathrm{C}$ isolated from the seeds of Celosia argentea (Amaranthaceae), inhibit the polymerization of tubulin [34]. Obviously, it is of significance to study the relationship of structure-activity of mentioned above compounds, including TBMS1.

The atypical tubulin turbidity profile-increasing inhibition of tubulin polymerization at low concentrations, with maximal and about 50\% inhibition occurring with concentrations $10 \mu \mathrm{M}$ and higher-was observed with TBMS1. Such patterns have been reported by other authors with the explanation suggested of limited aqueous solubility [35]. Due to hydrophobic nature of the pockets of the binding sites of paclitaxel, vinca alkaloid and colchicine, it is quite surprised that TBMS1 as a hydrophilic watersoluble compound is able to interact with tubulin. It seemed as if we could not think of the right explanation. Perhaps TBMS1 is a partial agonist.

Anti-microtubule agents are tubulin binding compounds. Tubulin binding molecules interfere with the dynamic instability of microtubules and thereby arrest mitotic cells in the M-phase of the cell division cycle, finally leading to apoptotic cell death. Tubulin binding molecules from nature include colchicine, the vinca alkaloids vinblastine and vincristine, rhizoxin, maytansine, combretastatin A4, epothilone, paclitaxel, and dolastatin 10 [36] and dolastatin 15 [37]. To our current knowledge, natural compounds bind to distinct sites within $\beta$-tubulin and by destability or stabilization of microtubules, cause mitotic catastrophe [23]. Palitaxel and Taxotere are stabilizing tubulin inhibitors used clinically for the treatment of breast, ovarian, and non-small cell lung cancer, whereas vincristine and vinblastine are destabilizing tubulin inhibitors indicated for acute lymphatic leukemia, Hodgkin disease, and advanced breast cancer [38]. The tubulin inhibitors used for human cancer therapy have severe drawbacks, i.e., dose-limiting toxicity (especially neurotoxicity), marginal oral bioavailability and poor solubility, complex synthesis and isolation procedures with low yield, and most importantly, the development of drug resistance, which is a common phenomenon. Although TBMS1 is a natural compound with complex structure, its isolation procedures are not too complex, and the yields (1.85\%) are relatively high. Moreover, it is water-soluble, and has high oral bioavailability with acceptable therapeutic index. Therefore, TBMS1 is a highly attractive candidate of anti-tumor agent.

In summary, the anti-microtubule activity of TBMS1 probably results from its binding at the colchicine site of tubulin. Analysis of TBMS1 uptake kinetics by CNE-2Z cells displayed the initial markedly slow TBMS1 uptake and then gradually reaching an apparent maximum uptake near $18 \mathrm{~h}$. TBMS1 inhibits tubulin polymerization at higher concentrations. The findings may be of benefit to elucidating the cellular and molecular mechanisms underlying the anti-tumor effects of TBMS1.

Acknowledgment The authors thank Dr. Depu Yu for his great encouragement.

Open Access This article is distributed under the terms of the Creative Commons Attribution Noncommercial License which permits any noncommercial use, distribution, and reproduction in any medium, provided the original author(s) and source are credited.

\section{References}

1. Zhao XM (1983) Supplement to the compendium of materia medica (reprinted from the 1765 wood-engraved edition). The People's Medical Publishing House, Beijing, p 123

2. Wang YQ, Yu LJ, Zhu JL, Yang SY (1981) Studies on antitumor action of extracts of Bolbostemma paniculatum (Maxim.) Franquet. Shaanxi Med J 10:55

3. Kong F, Zhu D, Xu R, Fu Z, Zhou L, Iwashita T, Komura H (1986) Structural study of TBMS1, a constituent of tu-bei-mo. Tetrahedron Lett 27:5765

4. Yu LJ, Ma RD, Wang YQ, Nishino H (1994) Potent anti-tumor activity and low toxicity of tubeimoside I isolated from $\mathrm{Bol}$ bostemma paniculatum. Planta Med 60:204

5. Yu LJ, Ma RD, Wang YQ, Nishino H, Takayasu J, He WZ, Chang M, Zhen J, Liu WS, Fan SX (1992) Potent anti-tumorigenic effect of tubeimoside I isolated from the bulb of Bolbostemma paniculatum (Maxim.) Franquet. Int J Cancer 50:635 
6. Yu LJ, Ma RD, Yu TX (1996) Induction of morphological and functional differentiation of human promyelocytic leukemia cells (HL-60) by tubeimoside I. Planta Med 62:119

7. Wang CX, Ma RD, Yu LJ (2006) Inhibitory effects of tubeimoside I, a cyclic bisdesmoside isolated from Bolbostemma paniculatum, on metastases of mouse B16 melonoma and lewis lung carcinoma. Chin J Clin Pharmacol Ther 11:764

8. Hu Z, Ma RD, Yu LJ (2003) Effects of tubeimoside I on cell cycle and apoptosis of human myeloblastic leukemia cells (HL-60). Chin J Clin Oncol 30:163

9. Ma RD, Yu LJ, Su WM, Shao HY, Liao MN, He DM, Huang LZ (2004) Induction of cell cycle arrest and apoptosis by tubeimoside I isolated from Bolbostemma paniculatum in HeLa cells. Chin J Clin Pharmacol Ther 9:261

10. Ma RD,Weng XY, Yu LJ, Su WM, Shao HY, Liao MN, He DM, Huang LZ, Yu TX (2003) Apoptosis of human nasopharyngeal carcinoma CNE-2Z cell line induced by tubeimoside I isolated from Bolbostemma paniculatum. U S Chin J Limph Ocol 2:11

11. Schiff PB, Horwitz SB (1980) Taxol stabilizes microtubules in mouse fibroblast cells. Proc Natl Acad Sci USA 77:1561

12. Rowinsky EK (1997) The development and clinical utility of the taxane class of antimicrotubule chemotherapy agents. Annu Rev Med 48:353

13. Jordan A, Hadfield JA, Lawrence NJ, McGown AT (1998) Tubulin as a target for anticancer drugs: agents which interact with the mitotic spindle. Med Res Rev 18:259

14. Li Q, Sham H, Rosenberg S (1999) Antimitotic agents. Annu Rep Med Chem 34:139

15. Wang F. Ma RD, Yu LJ (2006) Role of mitochondria and mitochondrial cytochrome $\mathrm{C}$ in tubeimoside I-mediated apoptosis of human cervical carcinoma HeLa cell line. Cancer Chemother Pharmacol 57:389

16. Hu DH, Ma RD, Yu LJ (2003) Inhibition of angiogenesis by tubeimoside I. Chin Pharmacol Bull 19:715

17. Klauber N, Parangi S, Flynn E, Hamel E, D'Amato RJ (1997) Inhibition of angiogenesis and breast cancer in mice by the microtubule inhibitors 2-methoxyestradiol and taxol. Cancer Res $57: 81$

18. Gu SY, Zhao WP, Zeng Y, Tang WP, Zhao ML, Deng HH (1983) An epithelial cell line established from poorly differentiated nasopharyngeal carcinoma. Chin J Cancer 2:70

19. Hansen MB, Nielsen SE, Berq K (1989) Re-examination and further development of a precise and rapid dye method for measuring cell growth/cell kill. J Immunol Methods 119:203

20. Wei YL, Yang XM, Xu CG, Gao H, Sun WJ (2000) Quantitation of tubeimoside I by HPLC. Northwest J Pharm 15:107

21. Castoldi M, Popov AV (2003) Purification of brain tubulin through two cycles of polymerization-depolymerization in a high-molarity buffer. Protein Expr Purif 32:83

22. Lowry OH, Rosebrough NJ, Farr AL, Randall RJ (1951) Protein measurement with the Folin phenol reagent. J Biol Chem 193:265

23. Mínguez JM, Kim SY, Giuliano KA, Balachandran R, Madiraju C, Day BW, Curran DP (2003) Synthesis and biological assessment of simplified analogues of the potent microtubule stabilizer (+)-discodermolide. Bioorg Med Chem 11:3335
24. Mitsui-Saito M, Ohkubo S, Obara Y, Yanagisawa T, Kobayashi J, Ohizumi Y, Nakahata N (2002) Theonezolide A, a novel marine macrolide, induces drastic shape change in rabbit platelets by reorganization of microtubules. Thromb Res 108:133

25. Isbrucker RA, Cummins J, Pomponi SA, Longley RE, Wright AE (2003) Tubulin polymerizing activity of dictyostatin-1, a polyketide of marine sponge origin. Biochem Pharmacol 66:75

26. Kavallaris M, Tait AS, Walsh BJ, He L, Horwitz SB, Norris MD, Haber M (2001) Multiple microtubule alterations are associated with Vinca alkaloid resistance in human leukemia cells. Cancer Res 61:5803

27. Bai RL, Pettit GR, Hamel E (1990) Binding of dolastatin 10 to tubulin at a distinct site for peptide antimitotic agents near the exchangeable nucleotide and vinka alkaloid sites. J Biol Chem 265:17141

28. Edler MC, Fernandez AM, Lassota P, Ireland CM, Barrows LR (2002) Inhibition of tubulin polymerization by vitilevuamide, a bicyclic marine peptide, at a site distinct from colchicine, the vinca alkaloids, and dolastatin 10. Biochem Pharmacol 63:707

29. Nunez J, Fellous A, Francon J, Lennon AM (1979) Competitive inhibition of colchicine binding to tubulin by microtubule-associated proteins. Proc Natl Acad Sci USA 76:86

30. D’Amato RJ, Lin CM, Flynn E, Folkman J, Hamel E (1994) 2-Methoxyestradiol, an endogenous mammalian metabolite, inhibits tubulin polymerization by interacting at the colchicine site. Proc Natl Acad Sci USA 91:3964

31. Dixon M, Webb EC, Thorne CJR, Tipton KF (1979) Enzymes. Academic, New York, p 332

32. Tinley TL, Leal RM, Randall-Hlubek DA, Cessac JW, Wilkens LR, Rao PN, Mooberry SL (2003) Novel 2-methoxyestradiol analogues with antitumor activity. Cancer Res 63:1538

33. Tinley TL, Randall-Hlubek DA, Leal RM, Jackson EM, Cessac JW, Quada JC Jr, Hemscheidt TK, Mooberry SL (2003) Taccalonolides E and A: plant-derived steroids with microtubulestabilizing activity. Cancer Res 63:3211

34. Kobyashi J, Suzuki H, Shimbo K, Takeya K, Morita H (2001) Celogentins A-C, new antimitotic bicyclic peptides from the seeds of Celosia argentea. J Org Chem 66:6626

35. Cushman M, He HM, Lin CM, Hamel E (1993) Synthesis and evaluation of a series of benzylaniline hydrochlorides as potential cytotoxic and antimitotic agents acting by inhibition of tubulin polymerization. J Med Chem 36:2817

36. Bai R, Pettit GR, Hamel E (1990) Dolastatin 10, a powerful cytostatic peptide derived from a marine animal: inhibition of tubulin polymerization mediated through the vinca alkaloid binding domain. Biochem Pharmacol 39:1941

37. Bai R, Friedman SJ, Pettit GR, Hamel E (1992) Dolastatin 15, a potent antimitotic depsipeptide derived from Dolabella auricularia: interactions with tubulin and effects on cellular microtubules. Biochem Pharmacol 43:2637

38. Dutcher JP, Novik Y, O'Boyle K, Marcoullis G, Secco C, Wiernik PH (2000) 20th-century advance in drug therapy in oncology_Part II. J Clin Pharmacol 40:1079 